Discussion Paper No. 659

\title{
PROTECTIVE TRADE POLICIES \\ 'REDUCE' EMPLOYMENT: \\ A DYNAMIC OPTIMIZATION APPROACH
}

\author{
Yoshiyasu Ono
}

April 2006

The Institute of Social and Economic Research

Osaka University

6-1 Mihogaoka, Ibaraki, Osaka 567-0047, Japan 
April 2006

\title{
Protective Trade Policies 'Reduce’ Employment: A Dynamic Optimization Approach
}

\author{
by \\ Yoshiyasu Ono* \\ Osaka University
}

\begin{abstract}
Using a competitive two-country two-commodity monetary model with optimizing agents in which persistent unemployment arises, this paper examines the effects of trade restrictions on consumption and employment in the two countries. When facing unemployment, a country tends to impose an import restriction so that domestic firms will increase production and raise employment. However, this policy improves the current account and hence its currency appreciates, causing its products to lose international competitiveness. Therefore, employment and consumption eventually decrease in the country while in the foreign country its currency depreciates and hence employment and consumption increase.
\end{abstract}

JEL classification: F13, F41, F42

Keywords: persistent unemployment, trade restrictions, exchange-rate adjustment, dynamically optimizing agents.

Address: Institute of Social and Economic Research, Osaka University, 6-1, Mihogaoka, Ibaraki, Osaka, 567-0047, JAPAN

E-mail: ono@iser.osaka-u.ac.jp

* For useful comments I thank Y. Iida and participants in the Sophia Symposium 2005. This research is financially supported by the $21^{\text {st }}$ Century COE Program of the Ministry of Education, Culture, Sports, Science, and Technology. 


\section{Introduction}

In the 1980s the USA was annoyed by a huge trade deficit against Japan. Various US industries were threatened by massive Japanese exports and many employees were laid off. Consequently, trade frictions arouse in various industries, such as steel, color TV, automobiles, and microchips. As a new friction occurred, the US government imposed a trade restriction to protect a threatened industry under the belief that such a protection would provide a larger market to import-competing firms and hence increase employment. In reality, however, employment did not recover as expected. The US dollar then continued to rise against the Japanese yen, causing the price competitiveness of US products to deteriorate, and new trade frictions occurred one after another.

This paper examines the abovementioned process of unemployment and currency appreciation due to a trade restriction. In doing so it introduces a tariff or a quota into a two-country two-commodity continuous-time competitive model presented by Ono (2006) in which people rationally behave and wages and prices continue to adjust, albeit in a sluggish manner, and yet a persistent demand shortage arises under a liquidity trap. ${ }^{1}$ In this framework it is found that an import tariff/quota improves the current account and raises the value of the home currency, which increases the relative price of the home products. ${ }^{2}$ Moreover, the price rise is so high that employment eventually decreases in the home country. It in turn lowers the relative price of the foreign products and improves employment in the foreign country. Thus, a trade restriction is found to generate currency appreciation and worsen unemployment, as actually observed in the USA in the late 1980s and the early 1990s.

In the conventional analysis of optimal tariffs/quotas with full employment and perfect competition the optimal tariff for a small country is widely known to be zero. In a two-country setting a positive tariff benefits the tariff-imposing country and harms the other through an improvement in the terms of trade. Moreover, in the presence of unemployment, a positive tariff may seem even more beneficial since it protects an import-competing industry and raises employment. In fact, Choi and Beladi $(1993,1998)$ assume wage and interest-rate rigidities and show that a positive tariff is beneficial even in a small economy.

\footnotetext{
${ }^{1}$ It is an open-economy extention of Ono (1994, 2001), where persistent unemployment is found to arise within a closed-economy framework.

${ }^{2}$ In fact, a recent empirical research by Santos-Paulino and Thirlwall (2004) finds that a trade liberalization worsens the current account.
} 
However, in a small country with Harris-Todaro-type urban unemployment caused by fixed urban and flexible rural wages, Chen and Choi (1994) find that a negative tariff benefits the country. It is because they assume the country to import a capital-intensive commodity and thus an import promotion lowers the capital rent and raises the rural wage, which causes urban unemployment to decrease. Chao and Yip (2000) introduce a cash-in-advance constraint into a monetary economy with Harris-Todaro-type unemployment and find that a negative tariff can benefit the country. ${ }^{3}$ All of these studies consider a static framework and hence ignore the current-account adjustment that determines the exchange rate.

There are also some papers that analyze the effect of a tariff on the dynamic profile of the current account in a continuous-time dynamic optimization setting. They are e.g. Roldos (1991) with capital accumulation, Mansoorian (1993) with habit formation, and Ikeda (2003, 2006) with weakly non-separable intertemporal preferences. ${ }^{4}$ However, none of them consider the possibility of unemployment. Moreover, they consider a small country. ${ }^{5}$ Van Wijnbergen (1987) uses a two-period model with wage rigidity in the first period and analyzes the effect of a tariff on the current account and employment. Unlike the present analysis, however, it regards unemployment as a short-run phenomenon that disappears in the second period.

When analyzing unemployment in an open-economy dynamic framework, the new open economy macroeconomic models, e.g., Obstfeld and Rogoff (1995), Christiano, Eichenbaum and Evance (1997), Hau (2000), and Betts and Devereux (2000a, 2000b), are often utilized. ${ }^{6}$ They adopt a period analysis with monopolistic competition and nominal price/wage stickiness and assume that prices/wages can be modified only at the beginning of each period. In this setup, if a government imposes a trade restriction in the middle of a period, disequilibrium arises only in that period and full employment is achieved in the next period and thereafter. Hence they cannot deal with persistent unemployment, which the present paper focuses on.

In the following section 2 presents a basic structure of the model. Section 3 obtains conditions under which persistent unemployment arises. The effects of an import tariff on the exchange rate, the relative price, employment and consumption are examined in section 4 . It is

\footnotetext{
${ }^{3}$ There are also other types of distortions that cause a negative tariff to be beneficial. For example, under an oligopolistic vertical relationship Lahiri and Ono (1999) show a negative tariff to be beneficial. See also Larue and Gervais (2002) for the same possibility with oligopolistic distortions.

${ }^{4}$ Inoue (2000) adopts a two-period trade model and finds that a negative tariff can benefit the country.

${ }^{5}$ Ikeda (2006) analyzes a two-country case as well.

${ }^{6}$ See Lane (2001) for an extensive survey on the new open economy macroeconomics.
} 
shown that an import tariff that is aimed to raise employment in fact 'lowers' it by causing the exchange rate to appreciate. Section 5 proves the equivalence between a tariff and a quota in the presence of unemployment. Thus, a quota is shown to generate the same controversial effect as a tariff does. Finally, section 6 summarizes and concludes this paper.

\section{The Model}

Consider an economy with two countries, 1 and 2, in which the firm sector of country 1 (or 2) specializes in commodity 1 (or 2 ) and inputs labor $l$ (or $l^{*}$ ) to produce $y_{1}$ (or $y_{2}^{*}$ ). The production functions are

$$
y_{1}=\theta_{1} l, \quad y_{2} *=\theta_{2} l^{*},
$$

where input-output coefficients $\theta_{1}$ and $\theta_{2}$ are assumed to be constant. Given nominal commodity price $P_{1}\left(\right.$ or $P_{2}{ }^{*}$ ) and nominal wage $W\left(\right.$ or $W^{*}$ ), each firm sector maximizes profits:

$$
\left(\theta_{1} P_{1}-W\right) l, \quad\left(\theta_{2} P_{2}{ }^{*}-W^{*}\right) l^{*} .
$$

There are three kinds of assets, viz. an international interest-earning asset, the home currency and the foreign currency. ${ }^{7}$ Among the three the household sector of each country chooses two assets, the home currency and the international asset, since the foreign currency neither yields interest nor has liquidity. The nominal interest rates of the international asset in countries 1 and 2 are respectively $R$ and $R^{*}$. The no-arbitrage condition between the domestic and foreign interest rates requires

$$
R=\dot{\varepsilon} / \varepsilon+R^{*},
$$

where $\varepsilon$ is the exchange rate of country 1's currency against country 2's one and a dot implies a time derivative. Total asset $a$ (or $a^{*}$ ) consists of home currency $m$ (or $m^{*}$ ) and international asset $b$ (or $b^{*}$ ), all measured in real term, ${ }^{8}$ and thus each country’s asset constraint is

$$
a=b+m, \quad a^{*}=b^{*}+m^{*} .
$$

Since the government of country 1 imposes tariff $t$ on its import of commodity 2 while country 2 imposes no tariff, the nominal consumer prices of the two commodities are

$$
\begin{aligned}
& P_{1} \text { and }(1+t) \varepsilon P_{2} * \text { in country } 1, \\
& P_{1} / \varepsilon \text { and } P_{2} * \text { in the international market and country } 2 .
\end{aligned}
$$

Given these prices the household sectors respectively maximize

\footnotetext{
${ }^{7}$ Because of the production technology given by (1) the firm values are zero.

${ }^{8}$ Note that the real values of nominal variables in the two countries have different units since a tariff makes the
} 


$$
U=\int_{0}^{\infty}\left(u\left(c_{1}, c_{2}\right)+v(m)\right) \exp (-\rho s) d s, \quad U^{*}=\int_{0}^{\infty}\left(u^{*}\left(c_{1}^{*}, c_{2} *\right)+v^{*}\left(m^{*}\right)\right) \exp (-\rho s) d s,
$$

where they have the same subjective discount rate $\rho$. Utility from liquidity holding $v(m)$ and $v^{*}\left(m^{*}\right)$ satisfy

$$
v^{\prime}(m)>0, \quad v^{\prime \prime}(m)<0 ; \quad v^{* \prime}\left(m^{*}\right)>0, \quad v^{* \prime \prime}\left(m^{*}\right)<0 .
$$

In order for the consumer price index to be a function of only the prices of the two commodities, utility functions of consumption, $u\left(c_{1}, c_{2}\right)$ and $u^{*}\left(c_{1}^{*}, c_{2} *\right)$, are assumed to be

$$
\begin{gathered}
u\left(c_{1}, c_{2}\right)=(1 / \sigma) \ln \left(\kappa_{1} C_{1}{ }^{\sigma}+\kappa_{2} C_{2}{ }^{\sigma}\right), u^{*}\left(c_{1} *, c_{2}{ }^{*}\right)=(1 / \sigma) \ln \left(\kappa_{1} C_{1} *^{\sigma}+\kappa_{2} C_{2} *^{\sigma}\right), \\
\text { where } 1>\sigma>0 .
\end{gathered}
$$

Under the utility functions given above and commodity prices given by (5), consumer price index $P^{*}$ and real consumer prices of the two commodities $p_{1}{ }^{*}$ and $p_{2}{ }^{*}$ in the international market and country 2 are respectively

$$
\begin{aligned}
& P^{*}=1 /\left\{\kappa_{1}{ }^{1 /(1-\sigma)}\left(P_{1} / \varepsilon\right)^{-\sigma /(1-\sigma)}+\kappa_{2}{ }^{1 /(1-\sigma)} P_{2}{ }^{*-\sigma /(1-\sigma)}\right\}^{(1-\sigma) / \sigma}, \\
& p_{1}{ }^{*} \equiv\left(P_{1} / \varepsilon\right) / P^{*}=p_{1}(\omega)=\left[\kappa_{1}{ }^{1 /(1-\sigma)}+\kappa_{2}{ }^{1 /(1-\sigma)} \omega^{-\sigma /(1-\sigma)}\right]^{(1-\sigma) / \sigma}, \\
& p_{2}{ }^{*} \equiv P_{2}{ }^{*} / P^{*}=p_{2}(\omega)=\omega p_{1}(\omega)=\left[\kappa_{1}{ }^{1 /(1-\sigma)} \omega^{\sigma /(1-\sigma)}+\kappa_{2}{ }^{1 /(1-\sigma)}\right]^{(1-\sigma) / \sigma},
\end{aligned}
$$

where $\omega$ is the international relative price of commodity 2:

$$
\omega=\varepsilon P_{2} * / P_{1} .
$$

Since country 1 imposes a tariff on commodity 2, consumer price index $P$ and real prices $p_{1}$ and $p_{2}$ in country 1 are

$$
\begin{aligned}
& P=1 /\left\{\kappa_{1}{ }^{1 /(1-\sigma)} P_{1}{ }^{-\sigma /(1-\sigma)}+\kappa_{2}{ }^{1 /(1-\sigma)}\left[(1+t) \varepsilon P_{2}{ }^{*}\right]^{-\sigma /(1-\sigma)}\right\}^{(1-\sigma) / \sigma}, \\
& p_{1} \equiv P_{1} / P=p_{1}((1+t) \omega), \\
& p_{2} \equiv(1+t) \varepsilon P_{2} * / P=p_{2}((1+t) \omega),
\end{aligned}
$$

where the functional form of $p_{1}(\cdot)$ and that of $p_{2}(\cdot)$ are given in (7).

From (3), (7), (8) and (9) real interest rates $r$ and $r^{*}$ satisfy

$$
r-\delta((1+t) \omega) \dot{\omega} / \omega=r^{*}-\delta(\omega) \dot{\omega} / \omega,
$$

where function $\delta(\cdot)$ implies

$$
\begin{gathered}
\delta(\omega)=\kappa_{1}{ }^{1 /(1-\sigma)} /\left[\kappa_{1}{ }^{1 /(1-\sigma)}+\kappa_{2}{ }^{1 /(1-\sigma)} \omega^{-\sigma /(1-\sigma)}\right]=1+p_{1}{ }^{\prime}(\omega) \omega / p_{1}(\omega)=p_{2}{ }^{\prime}(\omega) \omega / p_{2}(\omega), \\
1>\delta(\omega)>0, \delta^{\prime}(\omega)=[\sigma /(1-\sigma)][\delta(1-\delta) / \omega]>0 .
\end{gathered}
$$

Note that real interest rates $r$ and $r^{*}$ can be mutually unequal although international asset trade is allowed since tariff $t$ causes the consumer price index to differ between the two countries.

relative price differ in the two countries. 
The flow budget equation of each household sector measured in real term is ${ }^{9}$

$$
\dot{a}=r a+w x-c-R m+z, \quad \dot{a}^{*}=r^{*} a^{*}+w^{*} x^{*}-c^{*}-R^{*} m^{*}+z^{*},
$$

where $w$ and $w^{*}$ are real wages, $x$ and $x^{*}$ actual labor supplies, $z$ and $z^{*}$ real lump-sum transfers, and $c$ and $c^{*}$ real total consumption represented by

$$
c=p_{1} c_{1}+p_{2} c_{2}, \quad c^{*}=p_{1}{ }^{*} c_{1} *+p_{2}{ }^{*} c_{2} * .
$$

Since each household's labor endowment is normalized to unity, $x$ and $x^{*}$ are

$$
x=\min (1, l), \quad x^{*}=\min \left(1, l^{*}\right) .
$$

Each household sector maximizes life-time utility (6) subject to (4) and (11). The intratemporal optimal conditions are

$$
\begin{gathered}
p_{1} c_{1}=\delta((1+t) \omega) c, \quad p_{2} c_{2}=[1-\delta((1+t) \omega)] c, \\
p_{1}{ }^{*} c_{1}{ }^{*}=\delta(\omega) c^{*}, \quad p_{2}{ }^{*} c_{2}{ }^{*}=[1-\delta(\omega)] c^{*},
\end{gathered}
$$

where $\delta(\cdot)$ is given by $(10)$. The intertemporal optimal conditions are

$$
\rho+\dot{c} / c+\pi=R=v^{\prime}(m) c, \quad \rho+\dot{C}^{*} / c^{*}+\pi^{*}=R^{*}=v^{* \prime}\left(m^{*}\right) c^{*},
$$

where $\pi$ (or $\pi^{*}$ ) represents the inflation rate of $P\left(\right.$ or $P^{*}$ ). The transversality conditions are

$$
\lim _{s \rightarrow \infty} \lambda(s) a(s) \exp (-\rho s)=0, \quad \lim _{s \rightarrow \infty} \lambda *(s) a^{*}(s) \exp (-\rho s)=0,
$$

where $\lambda$ and $\lambda^{*}$ are co-state variables for $a$ and $a^{*}$ respectively.

The equilibrium conditions of the two countries' money markets and that of the international asset market are

$$
\begin{aligned}
& \text { the money markets: } \quad M / P=m, \quad M^{*} / P^{*}=m^{*}, \\
& \text { the international asset market: }{ }^{10} \quad P b+\varepsilon P^{*} b^{*}=0 .
\end{aligned}
$$

Commodity prices $P_{1}$ and $P_{2}{ }^{*}$ are also assumed to adjust perfectly and hence at any point in time

$$
\begin{gathered}
\theta_{1} x=c_{1}+c_{1} *=\left[\delta((1+t) \omega) / p_{1}\right] c+\left[\delta(\omega) / p_{1} *\right] c^{*}, \\
\theta_{2} X^{*}=c_{2}+c_{2} *=\left\{[1-\delta((1+t) \omega)] / p_{2}\right\} c+\left\{[1-\delta(\omega)] / p_{2} *\right\} c^{*} .
\end{gathered}
$$

The labor market is internationally segmented and the adjustments of nominal wages in both countries are assumed to be sluggish. ${ }^{11}$ They move according to each unemployment rate:

\footnotetext{
${ }^{9}$ The nominal flow budget equation is $\dot{A}=W x+R P b-P c+P z$, where $A(=P a)$ represents total asset holdings measured in terms of yen. Equation (11) is derived from this equation and (4).

${ }^{10}$ Because of Walras's law for stock variables, (16) is valid if (15) holds.

11 This assumption is imposed in order to allow disequilibrium to occur in the labor market; otherwise the possibility of unemployment is avoided by definition. Note that even under this assumption the possibility of the
} 


$$
\dot{W} / W=\alpha(l-1), \quad \dot{W}^{*} / W^{*}=\alpha^{*}\left(l^{*}-1\right) .
$$

From (2), (18), and the perfect adjustment of $P_{1}$, if $\theta_{1} P_{1}>W, l=\infty$, causing $W$ to adjust immediately. If $\theta_{1} P_{1}<W, l=0$ and hence commodity supply is zero, causing $P_{1}$ to jump upward. Thus, $\theta_{1} P_{1}$ always equals $W$. In this case $l$ can take any finite value and thus equals the actual employment level. After all $P_{1}$ and $W$ move in parallel and follow (18) where $l=x$. The movements of $P_{2}{ }^{*}$ and $W^{*}$ analogously obtain. In sum,

$$
\begin{gathered}
p_{1} \theta_{1}=w(=W / P), \quad p_{2} * \theta_{2}=w^{*}\left(=W^{*} / P^{*}\right), \\
\dot{P}_{1} / P_{1}=\dot{W} / W=\alpha(x-1), \quad \dot{P}_{2} * / P_{2} *=\dot{W}^{*} / W^{*}=\alpha^{*}\left(x^{*}-1\right) .
\end{gathered}
$$

From these equations and the definition of $\delta(\omega)$ given in (10), $\pi$ and $\pi^{*}$ are

$$
\pi=\alpha(x-1)+[1-\delta((1+t) \omega)] \dot{\omega} / \omega, \quad \pi^{*}=\alpha^{*}\left(x^{*}-1\right)-\delta(\omega) \dot{\omega} / \omega .
$$

The government of country 1 transfers tariff revenue $t \varepsilon P_{2}{ }^{*} c_{2} / P$ to the household sector in a lump-sum manner while that of country 2 imposes no tariff. Therefore, from (9) one derives

$$
z=t p_{2} C_{2} /(1+t), \quad z^{*}=0 .
$$

Applying these equations and (15) to (11) yields the dynamics of the two countries' international asset holdings:

$$
\dot{b}=r b+p_{1} \theta_{1} x-p_{1} c_{1}-p_{2} c_{2} /(1+t), \quad \dot{b}^{*}=r^{*} b^{*}+p_{2} * \theta_{2} X^{*}-p_{1}^{*} c_{1} *-p_{2} * c_{2} * .
$$

From (3), (7)-(9), (16) and (17) it is found that one of the two equations in (20) implies the other.

\section{The Steady State with Unemployment}

This section explores the condition under which persistent unemployment arises. In the steady state $c$ stays constant, and thus from (13)

$$
r=\rho, \quad r^{*}=\rho .
$$

Since $b$ and $b^{*}$ then stay constant, ${ }^{12}$ from (12) and (20),

$$
\begin{gathered}
\dot{b}=\rho b+p_{1}((1+t) \omega) \theta_{1} x-c[1+t \delta((1+t) \omega)] /(1+t)=0, \\
\dot{b}^{*}=\rho b^{*}+p_{2}(\omega) \theta_{2} x^{*}-c^{*}=0 .
\end{gathered}
$$

If full employment obtains in this state,

$$
x=1, \quad x^{*}=1 .
$$

full employment steady state is not eliminated. In fact, the full employment steady state is presented in section 3. See van der Ploeg (1993) for the same type of sluggish price adjustment.

12 Otherwise, the transversality condition is not satisfied. 
Therefore, from (21),

$$
\begin{gathered}
c=\left(p_{1} \theta_{1}+\rho b\right)(1+t) /[1+t \delta((1+t) \omega)], \\
c^{*}=p_{2} * \theta_{2}+\rho b^{*} .
\end{gathered}
$$

Substituting (22) and (23) into the first equation of (17) gives the equation that $\omega$ has to satisfy. It is

$$
\begin{gathered}
\left\{[1-\delta((1+t) \omega)] \theta_{1}-\rho b(1+t) \delta((1+t) \omega) / p_{1}\right\} /[1+t \delta((1+t) \omega)] \\
=\left(p_{2}^{*} \theta_{2}+\rho b^{*}\right) \delta(\omega) / p_{1} *
\end{gathered}
$$

Note that $c, c^{*}$ and $\omega$ are independent of $m$ or $m^{*}$. Once $c$ and $c^{*}$ are determined by (23) and (24), from (13), (19) and (22) $m$ and $m^{*}$ are obtained so that they satisfy

$$
v^{\prime}(m) c=\rho, \quad v^{* \prime}\left(m^{*}\right) c^{*}=\rho .
$$

Now suppose the possibility of a liquidity trap. Liquidity demand functions imply the relationship between $R$ and $m$ for a given $c$ and that between $R^{*}$ and $m^{*}$ for a given $c^{*}$ derived from (16). They are

$$
R=v^{\prime}(m) C, \quad R^{*}=v^{* \prime}\left(m^{*}\right) C^{*} .
$$

Since $v^{\prime \prime}(m)<0$ and $v^{* \prime \prime}\left(m^{*}\right)<0, R$ (or $R^{*}$ ) is negatively related to $m$ (or $m^{*}$ ). If $v^{\prime}(m)$ and $v^{* \prime}\left(m^{*}\right)$ have positive lower bounds, ${ }^{13}$

$$
v^{\prime}(\infty)=\beta>0, \quad v^{*^{\prime}}(\infty)=\beta^{*}>0,
$$

$R$ (or $R^{*}$ ) decreasingly approaches a constant level $\beta c$ (or $\beta^{*} c^{*}$ ) as $m$ (or $m^{*}$ ) increases. It never becomes lower than $\beta c$ (or $\beta^{*} c^{*}$ ), implying a liquidity trap.

In the presence of the liquidity trap, the solutions of $m$ and $m^{*}$ that satisfy (25) may not exist. In fact, from (26) and (27),

$$
\begin{aligned}
& \beta c \geq \rho \Leftrightarrow \text { the } m \text { does not exist. } \\
& \beta^{*} c^{*} \geq \rho \Leftrightarrow \text { the } m^{*} \text { does not exist. }
\end{aligned}
$$

In the above inequalities $c$ and $c^{*}$ take the values derived from (23) and (24). From (27) and (28) it is evident that, if the $m$ that satisfies the first equation of (25) does not exist, the left-hand side of the equation exceeds the right-hand side for any $m$, implying that the desire for saving exceeds that for consumption if the consumption level is so high as to attain full employment. Therefore, a demand shortage arises. The appendix exhibits the range of $b$ in which the two

\footnotetext{
${ }^{13}$ Keynes (1936, Ch.17) mentions that this is an essential property of money and that under this property a shortage of effective demand obtains. See Ono (1994, pp.31-33; 2001) for the implication of this property on the effective-demand shortage caused by a liquidity trap. This property is empirically shown by Ono (1994, chap.3) using the GMM (Generalized Method of Moments), and more extensively by Ono, Ogawa, and Yoshida (2004) using both a parametric and a non-parametric approach.
} 
inequalities in (28) are vaild.

Let us next obtain the steady state when both conditions in (28) hold and hence the two countries face a shortage of demand. In this state prices and wages continue to decline and $v^{\prime}(m)$ and $v^{* \prime}\left(m^{*}\right)$ converge to $\beta$ and $\beta^{*}$ respectively. ${ }^{14}$ Therefore, from (13) and (19) in which $c, c^{*}$, and $\omega$ stay constant, one finds

$$
\beta c=\rho+\alpha(x-1), \quad \beta^{*} c^{*}=\rho+\alpha^{*}\left(x^{*}-1\right),
$$

where $x$ and $x^{*}$ are given as functions of $\omega, c$ and $c^{*}$ in (17). From (17) and (29), $c$ and $c^{*}$ are

$$
\begin{aligned}
c & =f\left(c^{*}, \omega ; t\right)=\left[(\rho-\alpha) / \beta+c^{*} \delta(\omega) \alpha /\left(\beta p_{1}^{*} \theta_{1}\right)\right] /\left[1-\delta((1+t) \omega) \alpha /\left(\beta p_{1} \theta_{1}\right)\right], \\
c^{*} & =f^{*}(c, \omega ; t) \\
& =\left\{\left(\rho-\alpha^{*}\right) / \beta^{*}+c[1-\delta((1+t) \omega)] \alpha^{*} /\left(\beta^{*} p_{2} \theta_{2}\right)\right\} /\left[1-(1-\delta(\omega)) \alpha^{*} /\left(\beta^{*} p_{2}^{*} \theta_{2}\right)\right] .
\end{aligned}
$$

These two curves are shown by figure 1 . Note that the figure is illustrated so that for a given $\omega$ $c$ is positive even if $c^{*}$ is zero, that an increase in $c^{*}$ raises $c$, and that the intersection point exists. These properties are satisfied under the following conditions:

$$
\begin{gathered}
A \equiv\left[1-\delta((1+t) \omega) \alpha /\left(\beta p_{1} \theta_{1}\right)\right]\left[1-(1-\delta(\omega)) \alpha^{*} /\left(\beta^{*} p_{2} * \theta_{2}\right)\right] \\
-\left\{\delta(\omega) \alpha /\left(\beta p_{1} * \theta_{1}\right)\right\}\left\{[1-\delta((1+t) \omega)] \alpha^{*} /\left(\beta^{*} p_{2} \theta_{2}\right)\right\}>0, \\
\rho>\alpha, \quad \rho>\alpha^{*} .
\end{gathered}
$$

From the two equations in (30), $c$ and $c^{*}$ are determined as functions of $\omega$ and $t$.

$$
\begin{gathered}
c=\left\{[(\rho-\alpha) / \beta]\left[1-(1-\delta(\omega)) \alpha^{*} /\left(\beta^{*} p_{2} \theta_{2}\right)\right]+\left[\left(\rho-\alpha^{*}\right) / \beta^{*}\right] \delta(\omega) \alpha /\left(\beta p_{1} * \theta_{1}\right)\right\} / A, \\
c^{*}=\left\{\left[\left(\rho-\alpha^{*}\right) / \beta^{*}\right]\left[1-\delta((1+t) \omega) \alpha /\left(\beta p_{1} \theta_{1}\right)\right]\right. \\
\left.+[(\rho-\alpha) / \beta][1-\delta((1+t) \omega)] \alpha^{*} /\left(\beta^{*} p_{2} \theta_{2}\right)\right\} / A,
\end{gathered}
$$

where $A$ is given by (31). In figure 1 point E represents $c$ and $c^{*}$ that satisfy (32). By applying these functions and (29) to the first equation in (21) and equalizing it to zero one finds $\omega$ that balances the current account. We here assume the current account function to satisfy the Marshall-Lerner condition ( $\partial \dot{b} / \partial \omega>0$ ). Since from (9), (10), (21), (29), (31) and (32),

$$
\begin{gathered}
\omega \partial \dot{b}(\omega, t) /\left.\partial \omega\right|_{t=0} \\
=[\delta(1-\delta) /(1-\sigma)]\left(c+c^{*}\right)\left\{\left[1-\alpha /\left(\beta p_{1} \theta_{1}\right)\right]\left[1-\alpha^{*} /\left(\beta^{*} p_{2} * \theta_{2}\right)\right] / A-(1-\sigma)\right\},
\end{gathered}
$$

the Marshall-Lerner condition is rewritten as ${ }^{15}$

$$
\partial \dot{b}(\omega, t) / \partial \omega>0 \Leftrightarrow\left[1-\alpha /\left(\beta p_{1} \theta_{1}\right)\right]\left[1-\alpha^{*} /\left(\beta^{*} p_{2} * \theta_{2}\right)\right] / A-(1-\sigma)>0 .
$$

\footnotetext{
${ }^{14}$ See Ono (2006) for the stability of the present dynamics when $t=0$.

${ }^{15}$ It is valid when $\sigma$ is close to 1 and hence the two commodities are close substitutes to each other. See Ono (2006) for this property.
} 
Once $\omega$ is thus determined, from (32) $c$ and $c^{*}$ obtain. From (13) the steady-state levels of $R$ and $R^{*}$ are

$$
R=\beta c, \quad R^{*}=\beta^{*} c^{*} .
$$

Therefore, from (3) $\dot{\varepsilon} / \varepsilon$ is

$$
\dot{\varepsilon} / \varepsilon=\beta c-\beta^{*} c^{*} .
$$

From (28) and (29) $x$ and $x^{*}$ are smaller than 1 in this state, and thus all nominal prices and wages continue to decline and $m$ and $m^{*}$ continue to expand. Nevertheless, the two transversality conditions in (14) hold since from (13) and (15)

$$
\dot{m} / m=-\pi=\rho-\beta c<\rho, \quad \dot{m}^{*} / m^{*}=-\pi^{*}=\rho-\beta^{*} c^{*}<\rho .
$$

\section{An Import Tariff}

This section focuses on the case where both countries face unemployment, and examines the effect of country 1's import tariff on the exchange rate and the two countries' consumption and employment. The effect of the tariff is examined in the neighborhood where

$$
t=0 .
$$

In this case (34) reduces to

$$
A \equiv \delta\left[1-\alpha /\left(\beta p_{1} \theta_{1}\right)\right]+(1-\delta)\left[1-\alpha^{*} /\left(\beta^{*} p_{2} * \theta_{2}\right)\right]>0 .
$$

Since $\left[1-\alpha /\left(\beta p_{1} * \theta_{1}\right)\right]\left[1-\alpha^{*} /\left(\beta^{*} p_{2}{ }^{*} \theta_{2}\right)\right]$ is positive under the Marshall-Lerner condition given by (34), the above property implies

$$
1-\alpha /\left(\beta p_{1} \theta_{1}\right)>0, \quad 1-\alpha^{*} /\left(\beta^{*} p_{2} * \theta_{2}\right)>0 .
$$

From (7), (9) and (16), country 1's real asset holding $b$ is

$$
b=-b^{*}\left\{\kappa_{1}{ }^{1 /(1-\sigma)}+\kappa_{2}{ }^{1 /(1-\sigma)}[(1+t) \omega]^{-\sigma /(1-\sigma)}\right\}^{(1-\sigma) / \sigma} /\left\{\kappa_{1}{ }^{1 /(1-\sigma)}+\kappa_{2}{ }^{1 /(1-\sigma)} \omega^{-\sigma /(1-\sigma)}\right\}^{(1-\sigma) / \sigma} .
$$

For simplicity, the international asset is assumed to be a real bond measured in terms of international prices and thus $b^{*}$ does not change when tariff $t$ is imposed. Thus, partially differentiating the above equation with respect to $t$ or $\omega$ and using (10) yields

$$
\partial b /\left.\partial t\right|_{t=0}=-(1-\delta) b, \quad \partial b /\left.\partial \omega\right|_{t=0}=0 .
$$

By applying (7), (9), (10), (29) and (37) to the total differentiations of the two equations in (21) it is found that, if relative price $\omega$ responds to tariff $t$ so that the current-account balance can recover, then

$$
\begin{aligned}
\mathrm{d} \dot{b} & =\left(\beta p_{1} \theta_{1} / \alpha-1\right) \mathrm{d} c-(1-\delta) p_{1} \theta_{1} x \mathrm{~d} \omega / \omega=0, \\
\mathrm{~d} \dot{b^{*}} & =\left(\beta^{*} p_{2} * \theta_{2} / \alpha^{*}-1\right) \mathrm{d} c^{*}+\delta p_{2} * \theta_{2} x^{*} \mathrm{~d} \omega / \omega=0 .
\end{aligned}
$$


By substituting the partial derivative of $c$ given in (32) with respect to $t$ :

$$
\partial c(\omega, t) / \partial t=\left\{\alpha \delta(1-\delta)\left[1-\alpha^{*} /\left(\beta^{*} p_{2} \theta_{2}\right)\right] /\left[\beta p_{1} \theta_{1}(1-\sigma)\right]\right\} c / A,
$$

to the first equation of (38), it is obtained that under (36)

$$
\partial \dot{b}(\omega, t) / \partial t=[\delta(1-\delta) /(1-\sigma)]\left[1-\alpha /\left(\beta p_{1} \theta_{1}\right)\right]\left[1-\alpha^{*} /\left(\beta^{*} p_{2} \theta_{2}\right)\right] c / A>0 .
$$

From (34) and (40), d $\omega / \mathrm{d} t$ satisfies

$$
\mathrm{d} \omega / \mathrm{d} t=-[\partial \dot{b}(\omega, t) / \partial t] /[\partial \dot{b}(\omega, t) / \partial \omega]<0 .
$$

From (26), (29), (35), (38) and (41), the effects of country 1's import tariff are

$$
\begin{gathered}
\mathrm{d} c / \mathrm{d} t<0, \mathrm{~d} x / \mathrm{d} t<0, \mathrm{~d} R / \mathrm{d} t<0, \mathrm{~d} \pi / \mathrm{d} t<0, \\
\mathrm{~d} c^{*} / \mathrm{d} t>0, \mathrm{~d} x^{*} / \mathrm{d} t>0, \mathrm{~d} R^{*} / \mathrm{d} t>0, \mathrm{~d} \pi^{*} / \mathrm{d} t>0, \\
\mathrm{~d} \omega / \mathrm{d} t<0, \mathrm{~d}(\dot{\varepsilon} / \varepsilon) / \mathrm{d} t<0 .
\end{gathered}
$$

Since neither $W$ nor $W^{*}$ can jump and $P_{1}$ and $P_{2}{ }^{*}$ are always set equal to $W / \theta_{1}$ and $W^{*} / \theta_{2}$ respectively under production technology (1), neither $P_{1}$ nor $P_{2} *$ can jump. Therefore, (8) and (41) imply exchange rate $\varepsilon$ to jump downward when tariff $t$ is imposed. Thereafter, exchange rate $\varepsilon$ moves along with $P_{1}$ and $P_{2} *$ so that $\omega$ stays constant over time. These properties are summarized as follows:

Proposition 1: An increase in a country's import tariff raises the value of its own currency against the other's and thus raises the relative price of its products $(1 / \omega)$. Consequently, its own employment and consumption decline whereas those of the other country expand. The appreciation speed of its own currency increases.

Intuitively, a rise in $t$ potentially improves the current account of the tariff-imposing country, causing the value of its currency to appreciate. Therefore, the other country's demand for its own commodity increases and eventually improves its employment and consumption. In turn, the other country's demand for the tariff-imposing country's product decreases so much that employment and consumption decrease in the tariff-imposing country.

The abovementioned mechanism seems quite opposite to what policy makers usually have in mind. ${ }^{16}$ It may be because they ignore the adjustment of the exchange rate. In fact, from (7), (9), (10) and (30), if the exchange rate is unchanged and thus relative price $\omega$ is invariant, a rise

\footnotetext{
${ }^{16}$ It is also different from the result of the conventional Mundell-Fleming with flexible exchange rates. An import tariff can either reduce or increase the tariff-imposing country's effective demand. See the appendix for this property.
} 
in the tariff rate shifts the $f$ curve in figure 1 upward and the $f^{*}$ curve leftward, as illustrated in figure 2. It implies that an import tariff raises employment and hence stimulates consumption in the tariff-imposing country while in the other country it reduces employment and consumption. Consequently, the intersection point of the two curves moves in the north-west direction, implying the tariff-imposing country's consumption to increase and the other's consumption to decrease. The former property is valid since $\partial c(\omega, t) / \partial t$ given by (39) is positive under (36) while the latter is derived from (32) and (36) as follows:

$$
\partial c^{*} / \partial t=-[\delta(1-\delta) /(1-\sigma)]\left[1-\alpha /\left(\beta p_{1} \theta_{1}\right)\right]\left[\alpha^{*} /\left(\beta^{*} p_{2} \theta_{2}\right)\right] c / A<0 .
$$

Thus, if relative price $\omega$ is fixed, a tariff protection raises consumption in the tariff-imposing country and lowers it in the other country, as is usually expected. However, this process accompanies an improvement in the current account. Thus, under the flexible exchange-rate regime the exchange rate appreciates, which harms the competitiveness of the tariff-imposing country's product. Proposition 1 implies that the harmful effect is so strong that the tariff-imposing country's employment and consumption decrease while the other country's employment and consumption increase.

\section{Tariff-Quota Equivalence}

If country 1 imposes quota $q$, instead of tariff $t$, on the import of commodity 2, the commodity market equilibrium conditions are

$$
\begin{gathered}
\theta_{1} X=\left[\delta\left(\omega_{q}\right) / p_{1}\left(\omega_{q}\right)\right] c+\left[\delta(\omega) / p_{1}{ }^{*}\right] c^{*}, \\
\theta_{2} X^{*}=q+\left\{[1-\delta(\omega)] / p_{2}{ }^{*}\right\} c^{*}, \quad q=\left\{\left[1-\delta\left(\omega_{q}\right)\right] / p_{2}\left(\omega_{q}\right)\right\} c,
\end{gathered}
$$

where $\omega_{q}$ is the relative price in country 1 under quota $q$. Since transfer $z$ equals the quota revenue and the nominal price of commodity 2 in country 1 is $p_{2}\left(\omega_{q}\right) P$, from $(42) z$ is

$$
z=\left(p_{2}\left(\omega_{q}\right) P-\varepsilon P_{2}^{*}\right) q / P=\left[1-\delta\left(\omega_{q}\right)\right]\left(1-\omega / \omega_{q}\right) c .
$$

Substituting this equation into (11) yields country 1's current account under quota q:

$$
\dot{b}=\rho b+p_{1} \theta_{1} x-c[1+\gamma \delta((1+\gamma) \omega)] /(1+\gamma)=0,
$$

where $\gamma$ is the mark-up ratio of the relative price of commodity 2 under quota $q$ :

$$
\omega_{q}=(1+\gamma) \omega .
$$

Since the relationship between $c$ and $x$ and that between $c^{*}$ and $x^{*}$ given in (29) still hold in the present case, from (29) and (42) $c$ and $c^{*}$ are determined as functions of $\omega$ and $q$. 
Substituting those functions into (43) gives the equilibrium level of $\omega$ and hence all variables are determined.

By replacing mark-up ratio $\gamma$ by tariff rate $t$, one finds that (42) and (43) are equivalent to (17) and the first equation of (21), respectively. Therefore, the equilibrium levels of all variables under tariff $t$ are the same as those under quota $q$ that makes the mark-up ratio of the price of commodity 2 equal $t$. This property is restated as follows:

Proposition 2: The equivalence between tariffs and quotas is valid in the stagnation steady state.

Since (7), (9) and (16) give

$$
b=-\left[p_{1}(\omega) / p_{1}\left(\omega_{q}\right)\right] b^{*},
$$

country 1's current account (43) reduces to

$$
\left[p_{1}(\omega) / p_{1}\left(\omega_{q}\right)\right] \dot{b}=-\rho b^{*}+\delta(\omega) c^{*}-p_{2}(\omega) q=0,
$$

where $p_{2}(\omega)$ and $\delta(\omega)$ are respectively given by (7) and (10) and $c^{*}$ is derived as a function of $\omega$ and $q$ from (29) and (42). Therefore, the Marshall-Lerner condition under quota $q$ is

$$
\begin{aligned}
& \{(1-\sigma) /[\delta(1-\delta)]\} \omega\left(\partial \dot{b} /\left.\partial \omega\right|_{\omega=\omega_{q}}\right) \\
& \quad=\left\{\left[1-\alpha^{*} /\left(\beta^{*} p_{2}^{*} \theta_{2}\right)\right] /\left[1-(1-\delta) \alpha^{*} /\left(\beta^{*} p_{2} * \theta_{2}\right)\right]\right\} c^{*}-(1-\sigma)\left(c+c^{*}\right)>0,
\end{aligned}
$$

Note that this value is estimated when quota $q$ is just non-binding and hence $\omega=\omega_{q}$.

Under (44) a negative relationship between tariff $t$ and equivalent quota $q^{\mathrm{e}}$ obtains as follows. Equations (33) and (40) give

$$
\begin{gathered}
(1 / \omega) \mathrm{d} \omega / \mathrm{d} t=-\left\{c\left[1-\alpha /\left(\beta p_{1} \theta_{1}\right)\right]\left[1-\alpha^{*} /\left(\beta^{*} p_{2} \theta_{2}\right)\right] / A\right\} \\
/\left\{\left[\left(1-\alpha /\left(\beta p_{1} \theta_{1}\right)\right)\left(1-\alpha^{*} /\left(\beta^{*} p_{2}{ }^{*} \theta_{2}\right)\right) / A-(1-\sigma)\right]\left(c+c^{*}\right)\right\}<0,
\end{gathered}
$$

Totally differentiating $c_{2}$ derived from the second equation of (12) and applying (10), the first equation of (37) and (45) to the result yields

$$
\begin{aligned}
& {[-\omega /(\mathrm{d} \omega / \mathrm{d} t)]\left\{p_{2}(1-\sigma) /[\delta(1-\delta)]\right\} \mathrm{d} c_{2} / \mathrm{d} t} \\
& =-c^{*}+(1-\sigma)\left(c+c^{*}\right)\left[1-(1-\delta) \alpha^{*} /\left(\beta^{*} p_{2}{ }^{*} \theta_{2}\right)\right] /\left[1-\alpha^{*} /\left(\beta^{*} p_{2}{ }^{*} \theta_{2}\right)\right],
\end{aligned}
$$

where the coefficient of $d c_{2} / \mathrm{d} t$ in the left-hand side is shown to be positive by (45). Therefore, under the Marshall-Lerner condition under quota $q$ given by (44) one naturally finds

$$
\mathrm{d} c_{2} / \mathrm{d} t<0,
$$

i.e., imposing an import tariff lowers the amount of import. It also implies the negative relationship between tariff $t$ and equivalent quota $q^{\mathrm{e}}$. 


$$
\mathrm{d} q^{\mathrm{e}} / \mathrm{d} t<0 .
$$

From this property and propositions 1 and 2 one finds the effect of an import restriction in general. An import tariff or quota first raises the domestic price of the foreign commodity and decreases its import, improving the restriction-imposing country's current account. It raises the value of its currency so that the current account recovers the equilibrium level and thus lowers the international (and foreign) relative price of the foreign commodity. Consequently, the foreign country's demand for its own commodity increases. Moreover, the magnitude of the increase is so large that it dominates the decrease in the restriction-imposing country's demand due to the restriction, and hence employment and consumption increase in the foreign country.

The appreciation of the restriction-imposing country's currency also raises the international relative price of its product, causing foreign demand for it to decrease. The magnitude of the decrease is so large that the world demand for it declines, and hence employment and consumption decrease in the restriction-imposing country.

Finally, from (33) and (45) the effect of a tariff (or an equivalent quota) on the restriction-imposing country's domestic price, $(1+t) \omega=\omega_{q}$, is derived. It satisfies

$$
\begin{aligned}
\{(1-\sigma) /[\delta(1-\delta)]\}\left(\partial \dot{b} /\left.\partial \omega\right|_{t=0}\right) \mathrm{d}[(1+t) \omega] / \mathrm{d} t \\
\quad=\left\{\left[1-\alpha /\left(\beta p_{1} \theta_{1}\right)\right]\left[1-\alpha^{*} /\left(\beta^{*} p_{2}{ }^{*} \theta_{2}\right)\right] / A-(1-\sigma)\right\} C^{*}-(1-\sigma) c,
\end{aligned}
$$

where the coefficient of $c^{*}$ in the right-hand side is positive because of the Marshall-Lerner condition under tariff $t$ given by (34). Thus, $\mathrm{d}[(1+t) \omega] / \mathrm{d} t$ and $\mathrm{d} \omega_{q} / \mathrm{d} q$ can either be positive or negative depending on $c^{*} / c$, the relative size of the two countries' consumption. Proposition 1 implies that import tariff $t$ raises the value of its own currency and thus reduces $\omega$, the international relative price of the import commodity. If $c^{*}$ is much smaller than $c$, the reduction in $\omega$ is so much that it dominates the increase in the tariff and decreases the domestic relative price of the import commodity, $(1+t) \omega=\omega_{q}$. Otherwise, the domestic relative price naturally rises.

Surprisingly, if the former is the case, which occurs when the restriction-imposing country is much larger than the other, its demand for the home product decreases more than that for the foreign product does although an import restriction is imposed on the foreign product.

\section{Conclusions}

An import restriction, viz. a tariff or a quota, is broadly believed to raise domestic employment and thus it tends to be imposed especially when a country faces serious 
unemployment. When such a policy is considered, the exchange rate adjustment is often ignored. If the exchange-rate adjustment is taken into account, however, the result is quite different from such a belief. Using a dynamic optimization model with a liquidity trap and persistent stagnation, this paper finds that an import tariff/quota reduces employment and consumption in the restriction-imposing country and increases them in the other country as a result of the exchange-rate adjustment.

The mechanism is the following. An import tariff reduces import and thus improves the current account. It leads the home currency to appreciate against the foreign currency so that the current account recovers the equilibrium level, causing the international relative price of the home commodity to rise. If the economy is under a liquidity trap and a shortage of effective demand occurs, the appreciation of the home currency is so high that the amount of home production decreases. Consequently, unemployment becomes worse and consumption decreases. The appreciation of the home currency also implies a reduction in the price of the foreign commodity. The reduction is so large that the world demand for the foreign product expands and hence both employment and consumption increase in the foreign country although its export is restricted by the importing country. Since the equivalence of a tariff and a quota still holds in the stagnation steady state, the same argument applies to the case of an import quota. 


\section{Appendix}

\section{Conditions for the stagnation steady state to obtain:}

In the text I examine the effects of trade restrictions in the neighborhood where $t=0$. Thus, I assume $t=0$ and obtain the region of $b$ in which the two inequalities of (28) are both valid.

From (7), (8), (23) and (24), $c$ and $c^{*}$ are

$$
\begin{aligned}
& c=\kappa_{1} \theta_{1}{ }^{\sigma}\left(\kappa_{1} \theta_{1}{ }^{\sigma}+\kappa_{2} \theta_{2}{ }^{\sigma}\right)^{(1-\sigma) / \sigma}+\rho b, \\
& c^{*}=\kappa_{2} \theta_{2}{ }^{\sigma}\left(\kappa_{1} \theta_{1}{ }^{\sigma}+\kappa_{2} \theta_{2}{ }^{\sigma}\right)^{(1-\sigma) / \sigma}-\rho b .
\end{aligned}
$$

Therefore, conditions (28) reduce to

$$
\rho / \beta-\kappa_{1} \theta_{1}{ }^{\sigma}\left(\kappa_{1} \theta_{1}{ }^{\sigma}+\kappa_{2} \theta_{2}{ }^{\sigma}\right)^{(1-\sigma) / \sigma} \leq \rho b \leq \kappa_{2} \theta_{2}{ }^{\sigma}\left(\kappa_{1} \theta_{1}{ }^{\sigma}+\kappa_{2} \theta_{2}{ }^{\sigma}\right)^{(1-\sigma) / \sigma}-\rho / \beta^{*},
$$

where the first inequality is the condition under which the full-employment level of $m$ does not exist whereas the second one is the condition under which the full-employment level of $m^{*}$ does not exist.

Note that there is a region in which $\rho b$ that satisfies (A2) exists if both $\beta$ and $\beta^{*}$ are large enough or if $\theta_{1}$ and/or $\theta_{2}$ are large enough. For example, in a fully symmetric world, where

$$
\beta=\beta^{*}, \theta_{1}=\theta_{2}=\theta, \kappa_{1}=\kappa_{2}=\kappa, b=b^{*}(=0),
$$

(A2) is valid if either $\beta\left(=\beta^{*}\right)$ or $\theta$ is so large that

$$
\rho / \beta \leq 2^{(1-\sigma) / \sigma} \kappa^{1 / \sigma} \theta .
$$

This condition is essentially the same as that for the stagnation steady state to obtain in Ono (2001, 2006).

\section{Tariff Protections in the Mundell-Fleming Model:}

Since investment is ignored in the present setting, the IS and LM curves in the two countries are

$$
\begin{gathered}
y=c(y)+e_{x}\left(y^{*}, \omega\right)-i_{m}(y,(1+t) \omega), \\
y^{*}=c^{*}\left(y^{*}\right)-e_{x}\left(y^{*}, \omega\right)+i_{m}(y,(1+t) \omega), \\
M / P=L(R, y), \\
M^{*} / P^{*}=L^{*}\left(R, y^{*}\right),
\end{gathered}
$$

where $e_{x}$ is country 1 's export, $i_{m}$ is its import, and $y$ and $L$ (or $y^{*}$ and $L^{*}$ ) are respectively country 1's (or country 2's) effective demand and money demand. They naturally satisfy

$$
\begin{aligned}
& \partial e_{x} / \partial y^{*}>0, \quad \partial e_{x} / \partial \omega>0, \\
& \partial i_{m} / \partial y>0, \quad \partial i_{m} / \partial \omega<0,
\end{aligned}
$$




$$
\begin{aligned}
& \partial L / \partial R<0, \partial L / \partial y>0, \\
& \partial L^{*} / \partial R<0, \partial L^{*} / \partial y^{*}>0 .
\end{aligned}
$$

Note that under free international asset trade both countries face the same interest rate $R$. General price indices $P$ and $P^{*}$ are respectively given in (7) and (9) in which $P_{1}$ and $P_{2}{ }^{*}$ are fixed in the Mundell-Fleming setting.

By totally differentiating the four equations in (A3) and using (7) and (9) one obtains

$$
\begin{gathered}
K \mathrm{~d} y / \mathrm{d} t=\frac{(1-\delta) m \partial e_{x} / \partial \omega}{\partial L / \partial R}+\frac{\delta m^{*} \partial i_{m} / \partial \omega}{\partial L^{*} / \partial R}, \\
K \mathrm{~d} \omega / \mathrm{d} t=\frac{(1-\delta) m}{\partial L / \partial R}\left(1-c^{\prime}+\frac{\partial i_{m}}{\partial y}+\frac{1-c^{\prime}}{1-c^{*^{\prime}}} \frac{\partial e_{x}}{\partial y^{*}}\right)-\omega \frac{\partial i_{m}}{\partial \omega}\left(\frac{\partial L / \partial y}{\partial L / \partial R}+\frac{1-c^{\prime}}{1-c^{* \prime}} \frac{\partial L^{*} / \partial y^{*}}{\partial L^{*} / \partial R}\right),
\end{gathered}
$$

where from (7), (9), (A4) and (A5) $K$ is

$$
\begin{aligned}
K= & -\left(\frac{1}{\omega}\right)\left(\frac{(1-\delta) m}{\partial L / \partial R}+\frac{\delta m^{*}}{\partial L^{*} / \partial R}\right)\left(1-c^{\prime}+\frac{\partial i_{m}}{\partial y}+\frac{1-c^{\prime}}{1-c^{* \prime}} \frac{\partial e_{x}}{\partial y^{*}}\right) \\
& -\left(\frac{\partial e_{x}}{\partial \omega}-\frac{\partial i_{m}}{\partial \omega}\right)\left(\frac{\partial L / \partial y}{\partial L / \partial R}+\frac{1-c^{\prime}}{1-c^{* \prime}} \frac{\partial L^{*} / \partial y^{*}}{\partial L^{*} / \partial R}\right)>0 .
\end{aligned}
$$

(A4) and (A5) imply

$$
\begin{gathered}
\mathrm{d} y / \mathrm{d} t>\text { or }<0, \\
\mathrm{~d} \omega / \mathrm{d} t<0,
\end{gathered}
$$

i.e., in the Mundell-Fleming setting an import tariff may or may not raise the tariff-imposing country's effective demand, as stated in footnote 16 , while $\omega$ inevitably declines. Moreover, since totally differentiating the sum of the first two equations in (A3) gives the following property:

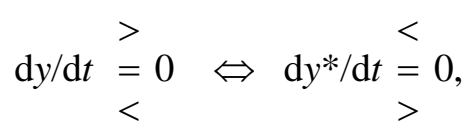

the effect on the other country's effective demand is also indeterminate. 


\section{References}

Betts, Caroline, and Michael B. Devereux, "Exchange Rate Dynamics in a Model of Pricing-to-Market,” Journal of International Economics, Vol.50, February 2000a, pp.215-244.

— and —, "International Monetary Policy Coordination and Competitive Depreciation: A Reevaluation”, Journal of Money, Credit, and Banking, Vol. 32, November 2000b, pp. 722-745.

Chao, Chi-Chur, and Chong K. Yip, "Urban Unemployment and Optimal Trade Policy in a Cash-in-Advance Economy,” Journal of Economics, Vol.71, February 2000, pp.59-77.

Chen, Jiong, and E. Kwan Choi, "Trade Policies and Welfare in a Harris-Todaro Economy,” Southern Economic Journal, Vol.61, October 1994, pp.426-434.

Choi, E. Kwan, and Hamid Beladi, "Optimal Trade Policies for a Small Open Economy,” Economica, Vol.60, November 1993, pp.475-486.

— and -, "Welfare Reducing Trade and Optimal Trade Policy," Japan and the World Economy, Vol.10, April 1998, pp.187-198.

Christiano, Lawrence J., Martin Eichenbaum, and Charles L. Evance, “Sticky Prices and Limited Participation Models of Money: A Comparison,” European Economic Review, Vol.41, June 1997, pp.1201-1249.

Hau, Harald, "Exchange Rate Determination: The Role of Factor Price Rigidities and Nontradeables,” Journal of International Economics, Vol.50, April 2000, pp.421-447.

Ikeda, Shinsuke, "Tariffs, Time Preference, and the Current Account under Weakly Nonseparable Preferences,” Review of International Economics, Vol.11, February 2003, pp.101-113.

__, “Luxury and Wealth,” International Economic Review, Vol.47, May 2006, pp.495-526.

Inoue, Tadashi, “The Optimal Tariff Formula in a Two-Period Economy,” Japanese Economic Review, Vol.51, December 2000, pp.596-604.

Keynes, John M., The General Theory of Employment, Interest and Money (London: Macmillan, 1936).

Lahiri, Sajal, and Yoshiyasu Ono, “Optimal Tariffs in the Presence of Middlemen,” Canadian Journal of Economics, Vol.32, February 1999, pp.55-70.

Lane, Philip R., “The New Open Economy Macroeconomics: A Survey,” Journal of 
International Economics, Vol.54, August 2001, pp.235-66.

Laure, Bruno, and Jean-Philippe Gervais, "Welfare-Maximizing and Revenue-Maximizing Tariffs with a Few Domestic Firms,” Canadian Journal of Economics, Vol.35, November 2002, pp.786-804.

Mansoorian, Arman, “Tariffs, Habit Persistence, and the Current Account,” Canadian Journal of Economics, Vol.26, February 1993, pp.194-207.

Obstfeld, Maurice, and Kenneth Rogoff, “Exchange Rate Dynamics Redux,” Journal of Political Economy, Vol.103, June 1995, pp.624-660.

Ono, Yoshiyasu, Money, Interest, and Stagnation, Oxford University Press, 1994.

—, "A Reinterpretation of Chapter 17 of Keynes's General Theory: Effective Demand Shortage Under Dynamic Optimization,” International Economic Review, Vol.42, February 2001, pp.207-236.

—, "International Asymmetry in Business Activity and Appreciation of a Stagnant Country's Currency”, Japanese Economic Review, Vol.57, March 2006, pp.101-120.

—, Kazuo Ogawa, and Atsushi Yoshida, "Liquidity Preference and Persistent Unemployment with Dynamic Optimizing Agents,” Japanese Economic Review, Vol.55, December 2004, pp.355-371.

Roldos, Jorge E., “Tariffs, Investment and the Current Account,” International Economic Review, Vol.32, February 1991, pp.175-194.

Santos-Paulino, Amedia, and Anthony P. Thirlwall, “The Impact of Trade Liberalization on Exports, Imports and the Balance of Payments of Developing Countries,” Economic Journal, Vol.114, February 2004, pp.F50-F72.

van der Ploeg, Frederick, “Channels of International Policy Transmission,” Journal of International Economics, Vol.34, May 1993, pp. 245-267.

van Wijnbergen, Sweder, "Tariffs, Employment and the Current Account: Real Wage Resistence and the Macroeconomics of Protection,” International Economic Review, Vol.28, October 1987, pp.691-706. 


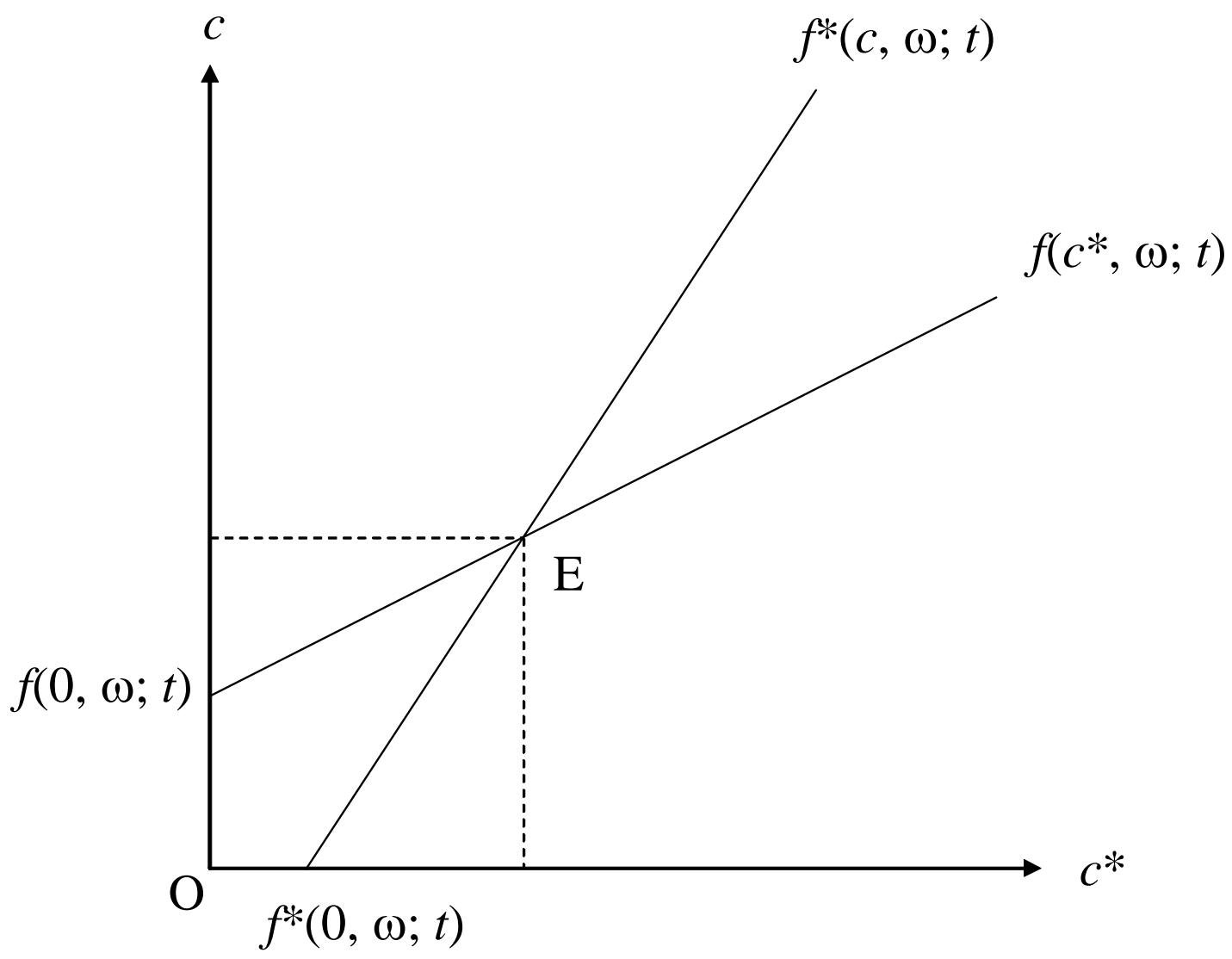

Figure 1: Interdependence of Consumption 


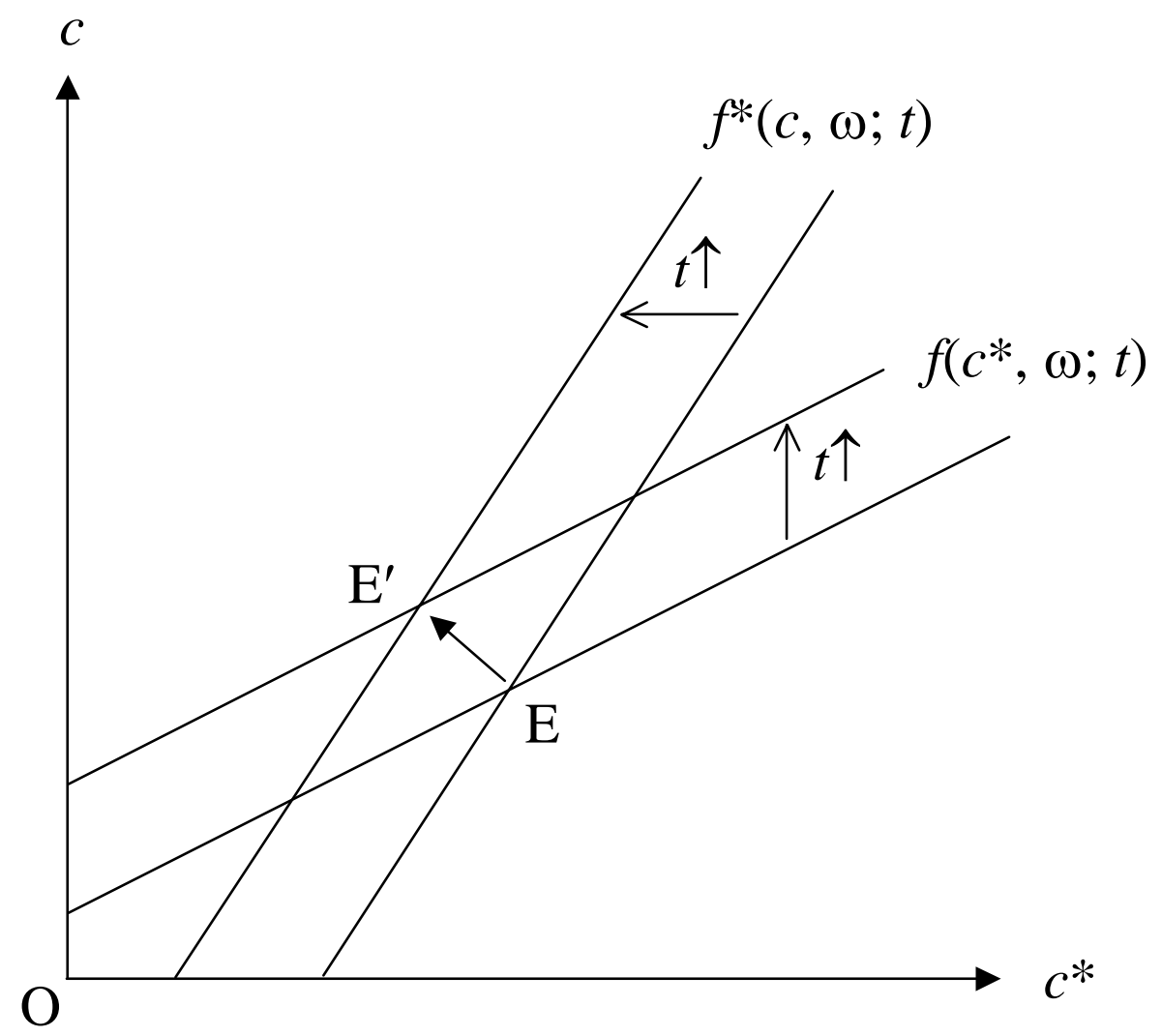

Figure 2: The Effect of a Tariff under Fixed Prices 